\title{
Commercial Cultivation of Australian Wild Oryza spp.: A Review and Conceptual Framework for Future Research Needs
}

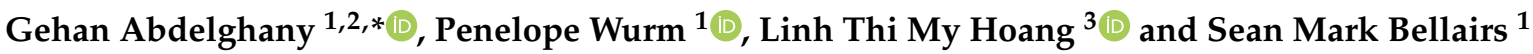 \\ 1 Research Institute for Environment and Livelihoods, Charles Darwin University, Darwin, NT 0909, Australia; \\ penny.wurm@cdu.edu.au (P.W.); sean.bellairs@cdu.edu.au (S.M.B.) \\ 2 Botany and Microbiology Department, Faculty of Science, Tanta University, Tanta 31527, Egypt \\ 3 Centre for Agriculture and the Bioeconomy, Queensland University of Technology (QUT), \\ Brisbane, QLD 4001, Australia; 1t.hoang@qut.edu.au \\ * Correspondence: gehan.abdelghany@cdu.edu.au
}

check for updates

Citation: Abdelghany, G.; Wurm, P.; Hoang, L.T.M.; Bellairs, S.M.

Commercial Cultivation of Australian Wild Oryza spp.: A Review and Conceptual Framework for Future Research Needs. Agronomy 2022, 12, 42. https://doi.org/ 10.3390/agronomy12010042

Academic Editors: Ganghua Li and Purushothaman Chirakkuzhyil Abhilash

Received: 17 November 2021 Accepted: 22 December 2021 Published: 25 December 2021

Publisher's Note: MDPI stays neutral with regard to jurisdictional claims in published maps and institutional affiliations.

Copyright: (c) 2021 by the authors. Licensee MDPI, Basel, Switzerland. This article is an open access article distributed under the terms and conditions of the Creative Commons Attribution (CC BY) license (https:// creativecommons.org/licenses/by/ $4.0 /)$.

\begin{abstract}
Wild Oryza species are being targeted for commercial cultivation due to their high nutritional grain profile, and their association with Aboriginal people in many regions. Australian wild Oryza species have potential as high-value, low-volume, culturally identified, and nutritious food, especially in gourmet food, tourism, restaurants, and value-added products. However, the basic agronomic protocols for their cultivation as a field crop are unknown. In this review, we identify the major factors supporting the commercial production of wild Oryza, including their stress-tolerant capacity, excellent grain quality attributes, and Indigenous cultural identification of their grains. The key challenges to be faced during the development of a wild rice industry are also discussed which include management barriers, processing issues, undesirable wild traits, and environmental concern. This manuscript proposes the use of agronomic research, in combination with breeding programs, as an overarching framework for the conceptualization and implementation of a successful wild rice industry, using the North American wild rice industry as a case study. The framework also suggests an integrated system that connects producers, industry, and government stakeholders. The suggested procedures for developing a wild rice industry in Australia are also applicable for other wild Oryza species.
\end{abstract}

Keywords: Australian wild Oryza; American wild rice; shattering; commercialization; rice grain quality; rice agronomy

\section{Introduction}

Wild Oryza species have been considered as sources of novel alleles in conventional rice breeding programs [1]. However, their commercial cultivation has also been targeted [2,3]. For example, Australian Oryza species produce a visually appealing, nutritious, and palatable grain for which there is a market as a local gourmet product in restaurants [2], and as a novelty product for tourists. Wild Oryza species possess advantageous features, supporting their commercialization. They have a wide stress tolerance capability for a range of biotic and abiotic stresses, enabling better acclimation to arid climatic conditions than commercial genotypes [4,5]. Further, an initial assessment of their grain quality attributes supports their commercial potential due to their high nutritional value, including unique starch properties [6-8]. Therefore, Australian Oryza species have the potential for commercial cultivation as a high-value, low-volume, culturally identified, and nutritious human food.

Establishing a wild rice industry could yield many essential benefits to First Nation people. For instance, cultivation of Australian wild Oryza for commercial purposes could potentially underpin small Indigenous enterprises in remote communities in northern Australia [9] where there is a lack of employment options. There is widespread interest in wildlife-based enterprises among Indigenous people in northern Australia [10], and 
in Australian Oryza specifically [2]. Indigenous Australians have been harvesting and consuming native rice species for many generations. Therefore, engagement in native rice-based industries could be an economic option for Indigenous people and a pathway to improve livelihoods and alleviate poverty throughout some communities [9].

The Oryza genus has two domesticated species, namely Oryza sativa from Asia and Oryza glaberrima from Africa, and 24 wild rice species [1]. Ten distinct genome types (AA, BB, CC, BBCC, CCDD, EE, FF, GG, KKLL, HHJJ) are identified within Oryza genus [11]. The wild species of Oryza have a global distribution (Figure 1A), including all tropical and subtropical regions of the world, throughout much of Africa, South-East Asia, Australasia, and Central and South America [12,13].

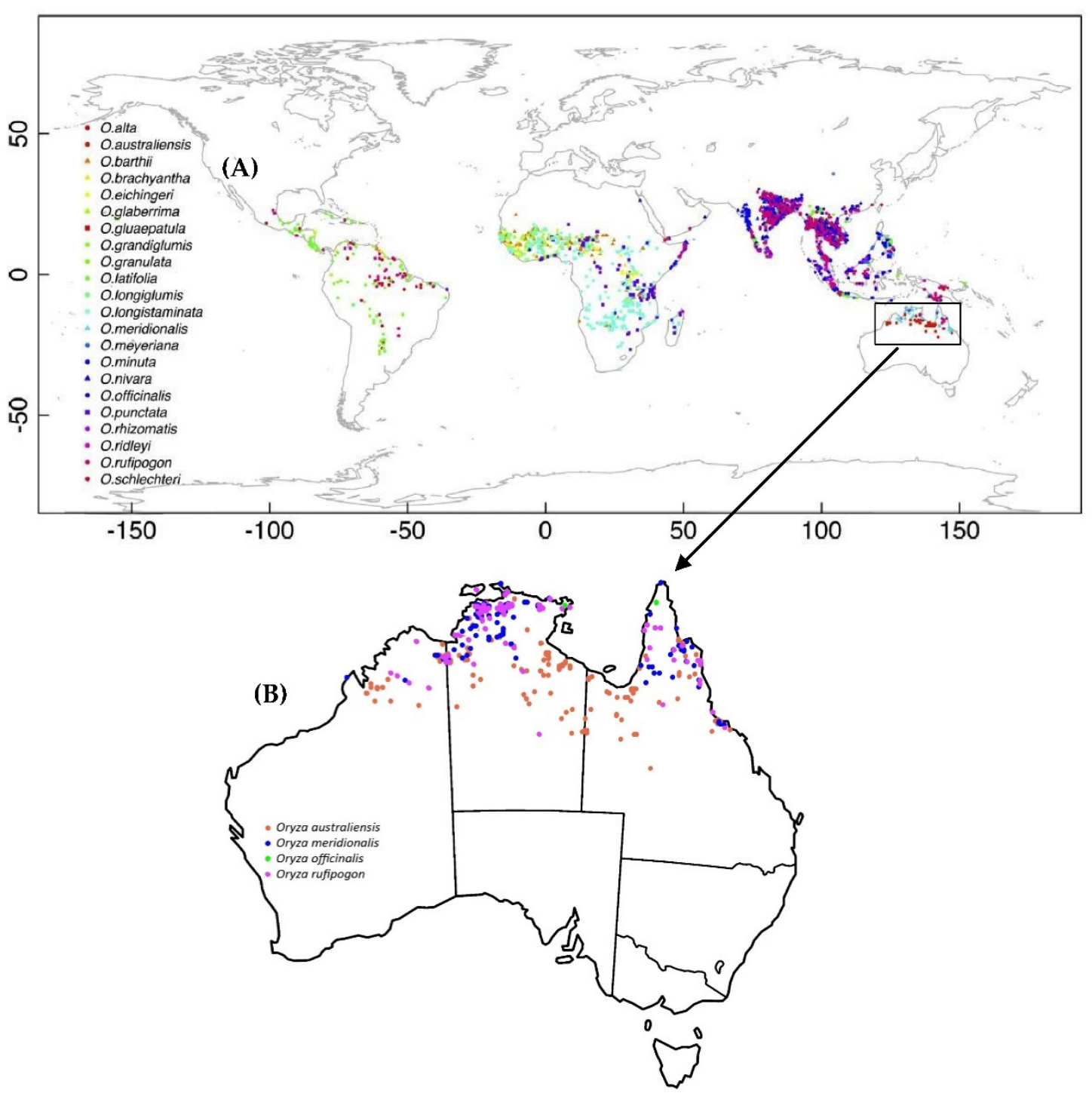

Figure 1. (A) Global distribution of all the wild Oryza species as described in [14], the phylogenetics and the genomic constitution of these wild relatives of rice are reviewed in [11]; (B) Distribution of wild Oryza species in Australia: O. rufipogon in violet, O. meridionalis in blue, O. officinalis in green, and O. australiensis in red. Based on occurrence records provided by [15].

Four wild Oryza species are native to northern Australia (Figure 1B). They are O. australiensis Domin, O. meridionalis Ng., O. officinalis Wall. ex G. Watt, and O. rufipogon Griff $[4,16]$. Both annual and perennial life forms of wild Oryza species are found in Australia. O. meridionalis Ng. is an abundant species endemic to Australia and New Guinea. 
It displays an annual life history and is morphologically distinguished by a short anther $(1.5-2.5 \mathrm{~mm})[12,13,16]$. O. rufipogon Griff is a widespread species with a distribution from Asia to Australia and its life cycle ranges from annual to perennial [12]. It has a longer anther length $(>3-7.4 \mathrm{~mm})$ than 0 . meridionalis. Anther length is the main feature used for distinguishing between them morphologically (Figure 2). Genome analysis has identified two distinct taxa within the Australian perennial O. rufipogon. These are Australian Oryza species (taxon A) which is morphologically similar to O. rufipogon and Australian Oryza species (taxon B) that is morphologically similar to O. meridionalis $[17,18]$. Taxon A and B have not been officially described yet $[18,19]$. O. australiensis Domin is a perennial species endemic to northern Australia. Whereas O. meridionalis and O. rufipogon belong to the AA genome type of the Oryza genus, O. australiensis is classified under the EE genome group of the Oryza genus [1,16]. It inhabits seasonally wet regions and survives the dry season as a rhizome. The fourth species, O. officinalis Wall. ex G. Watt belongs to the CC genome type of the Oryza genus and has only been found in two remote locations in north Australia, although it is widespread through southeast Asia [4].

Agricultural use of Australian native grasses has mainly been limited to supporting the grazing of livestock [20]. Although there are over 1300 native grass species in Australia [21] that are highly adapted to the harsh Australian environment, their application in agriculture has been very limited. However, some Australian native grasses have advantages for use in commercial cropping as food [22]. Microlaena stipoides is the first Australian cereal grass that was identified for domestication as a new cereal crop in 1895, and it has been recently domesticated and cultivated for commercial purposes [23,24]. It is cultivated in temperate Australian regions, with successful adaptation strategies for cooler climate conditions. Mutagenesis has enabled the modification of some undesirable traits, resulting in the generation of genotypes for commercial production [24].

Wild Oryza are underexploited native grass species in Australia. To date, most studies on Australian native Oryza species have focused on comparative genetics and genomics studies such as; (i) using novel alleles from Australian native rice for improving traits in cultigen rice [4]; (ii) assessing the phylogenetic relationship between Australian and Asian wild rices [18,25]; (iii) chloroplast and nuclear gene analysis [25,26]; (iv) heritability for grain yield under stress [27]; (v) ex-situ and in-situ conservation of the genetic resources [4]; (vi) stress tolerance capability of Australian wild Oryza [5,28]; and (vii) genome sequencing of wild Australian and Asian rices [19]. Although these studies provide a useful genetic background of these valuable species, they have not enabled an understanding of the optimum agronomic protocols for their commercial production as a native food.

A wild rice-based industry has succeeded in northern United States and southern Canada through the commercial production of wild rice Zizania palustris as a field crop [29]. The tremendous expansion of Zizania under field production was mainly due to the development of more shattering resistant cultivars, and the optimization of growing conditions [30]. Therefore, it changed from a local and gourmet commodity to an ingredient in international food markets.

In northern Australia, there is a strong interest in developing a wild rice industry based on Australian Oryza species. However, some major concerns have been identified. For example, some Australian Oryza species are high seed producers in the wild [1]. But, the inaccessibility of their natural habitats hinders the efficient wild harvesting of their seeds [2]. Wild harvest involves risking estuarine crocodile attack in the northern monsoonal Australian wetlands. Even with the use of modern airboats, accessibility can still be limited due to variable water levels when the seeds are ripening [2]. Consequently, the inter-annual variability of rainfall amount and pattern in northern Australia results in the risk of not being able to access the area at the right time in a given year. Therefore, wild harvest is not likely to enable a reliable seed supply for commercial purposes. Cultivation will be needed as a first initial step towards commercialization of Australian Oryza species, informed by thoroughly researched agronomic protocols, and awareness of the challenges that may arise. 

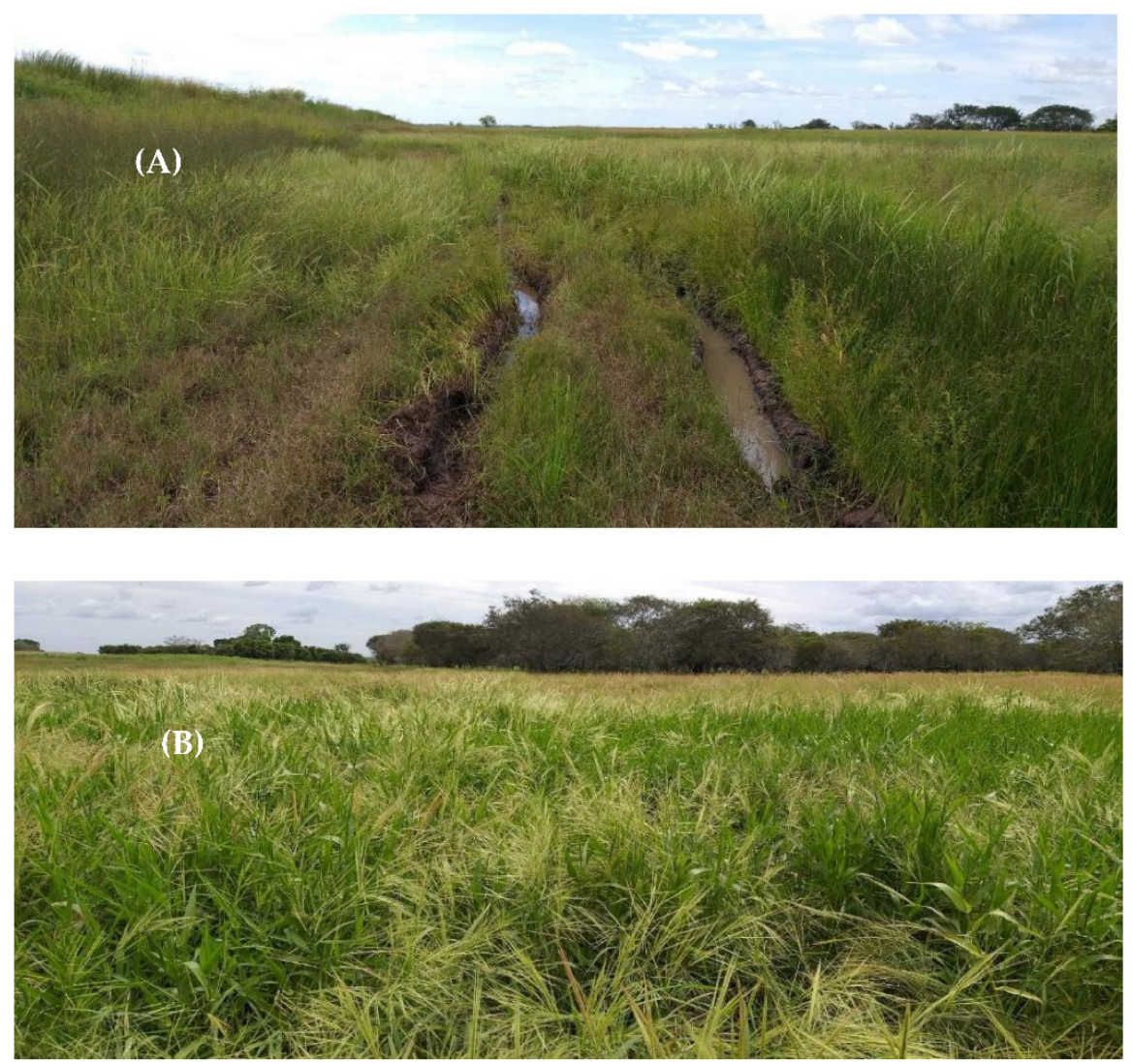

Figure 2. Australian wild Oryza populations growing in their natural habitat in northern Australia. (A) O. meridionalis and (B) O. rufipogon.

Further, several undesirable wild characteristics of Australian Oryza species could hinder their progress towards commercialization. This includes; (i) that some species are inherently poor seed producers; (ii) their shattering behavior is high; (iii) that some species exhibit low seed germination and low seed purity; (iv) that intractable dormancy issues are prevalent; and that (v) seed appendages result in handling problems [31,32]. Thus, harvested grain yields are inherently low in their unmanaged natural stands [1].

This review provides new perspectives on the potential commercialization of Australian wild Oryza species by; (i) summarizing the factors that suggest Australian Oryza species as promising candidates for establishing a rice industry based on wild species; (ii) identifying the key challenges that could hinder the development of this industry; (iii) using American wild rice as a case study to review the key factors for establishing a successful wild rice industry; and (iv) establishing a conceptual framework for developing a sustainable rice industry with wild Oryza species.

\section{Factors Suggesting Commercial Cultivation of Australian Oryza Species}

Australian wild Oryza have several advantageous features to aid in their commercial production (Figure 3). They exhibit a tolerance for a range of biotic and abiotic stresses as they occur in environments that are often harsh [4]. Also, their grain quality attributes suggest their potential success for commercial production as a high-quality product [6-8]. Further, the seed biology and seed dormancy breaking techniques of some Australian wild Oryza species are understood which could underpin their successful cultivation under paddy conditions [33]. 


\subsection{Environmental Stress Tolerance of Australian Wild Oryza}

Australian wild Oryza populations can tolerate a greater range of biotic and abiotic stresses than cultigen rice (i.e., tolerance towards heat, drought, salinity, and disease stresses) due to their unique genetic material. Their isolation from domesticated rice varieties prevents the contamination potential by gene flow from the cultivated rice genotypes [1,5]. The stress tolerance capacity could enable them to grow under varying environmental conditions, underpinning its successful cultivation and subsequent commercialization. The tolerances of these species to major environmental and biotic stresses are summarized below.

\begin{tabular}{|l|l|}
\hline (1) Stress tolerance capability & Grain appearance \\
\hline (2) Grain quality attributes & Grain color \\
\hline & Cooking, eating, sensory properties \\
\hline (3) Efficient seed dormancy-breaking & Grain nutritional quality \\
\hline
\end{tabular}

Figure 3. Factors supporting the establishment of a rice industry based on wild species in northern Australia.

\subsubsection{Heat Tolerance}

The heat tolerance of two Australian rice species, O. meridionalis and O. australiensis. has been investigated $[34,35]$. These species are adapted to the tropical climate of northern Australia where temperatures are usually $33^{\circ} \mathrm{C}$ in the monsoon growing season [36]. The heat tolerance of $O$. meridionalis was evaluated by comparing seedling development and photosynthetic rates at low $\left(27^{\circ} \mathrm{C}\right)$ and high temperatures $\left(45^{\circ} \mathrm{C}\right)$, with a Japonica cultivar. The higher growth rate of $O$. meridionalis at $45^{\circ} \mathrm{C}$ compared with cultigen rice, as well as a lower impact of heat on photosynthesis, indicated tolerance of $O$. meridionalis to the extreme heat conditions [34]. The thermotolerance of O. meridionalis is attributed to the heat-induced proteins, including rubisco activase (RCA), which are expressed during heat stress.

Similarly, heat tolerance and level of photosynthetic inhibition at elevated temperature were also investigated for O. australiensis, O. sativa. ssp. Japonica (cv. Amaroo) and Indica cv Doongara [35]. It has been reported that $O$. australiensis has superior heat tolerance compared with cultigen rice. This was attributed to the presence of a wild allelic form of 
RCA enzyme, which is thermally stable up to $42^{\circ} \mathrm{C}$, contrasting with RCA from $O$. sativa, which was inhibited at $36^{\circ} \mathrm{C}$. Thus, the thermotolerance capability of Australian Oryza species is due to an allele coding for greater thermal stability of RCA, enabling rubisco to remain active [35]. The thermotolerance of these valuable species will underpin their robust establishment in tropical Australia.

\subsubsection{Salinity Tolerance}

Soil salinity is a common issue in many rice-growing regions worldwide, affecting both plant development and productivity [28]. Trials to enhance the salt tolerance capability of many Asian commercial rice varieties of $O$. sativa - the most salt-sensitive of the major cereals-have yielded limited success, due to the complexity of the character and finite change in salt responses among $O$. sativa lines. However, it has been speculated that some accessions of Australian wild Oryza species, such as O. meridionalis and O. rufipogon, exhibit salinity tolerance as they naturally grow on floodplains developed on recent marine sediments [37]. The salinity tolerance of two Australian Oryza species, O. meridionalis and $O$. australiensis, has been investigated and compared with $O$. sativa cultivars from Indica backgrounds [28]. It was found that O. meridionalis and O. australiensis exhibited the least biomass reduction, chlorophyll content, and lowest average shoot $\mathrm{Na}+/ \mathrm{K}+$ ratio in response to salinity stress compared with other cultivated rice varieties under $80 \mathrm{mM}$ $\mathrm{NaCl}$ treatment [28]. The study of Nguyen et al. [5] also investigated the morphological, physiological, and molecular responses of $O$. australiensis under higher salt concentration at $150 \mathrm{mM} \mathrm{NaCl}$ treatment. It has been reported that $O$. australiensis rapidly accumulated proline, reducing the osmotic potential at an earlier stage of salt stress than commercial Indica and Japonica rices. O. australiensis also implements ion homeostasis as a defense strategy to cope with salinity stress. From a molecular perspective, $O$. australiensis activated synthesis genes of proline and suppressed the reveal of proline degradation allele $1 \mathrm{~h}$ after salinity stress exposure [5]. The fast aggregation of proline in O. australiensis enabled osmotic adjustment and salt tolerance in this native rice species. This enables O. australiensis to maintain relative water content and cell membrane integrity during salinity stress exposure [5]. Therefore, salinity tolerance of some Australian wild rice accessions could enable these species to be grown in more diverse or even problematic locations such as salinity exposed locations. This in turn could contribute to their potential commercial production.

\subsubsection{Drought Tolerance}

Wild Oryza species are reported to have genetic potential for drought resistance [27]. It is speculated that $O$. australiensis has a drought avoidance mechanism as the plant usually grows in seasonally wet habitats with a rhizome that enables it to survive the dry season [4,5]. Australian O. meridionalis also exhibits drought tolerance capability and better acclimation to arid climatic conditions than O. sativa L. [27]. The study investigated the genetic potential for drought resistance in Australian O. meridionalis and the contribution of its root architecture to drought avoidance, to derive drought-tolerant lines in cultigen rice. A back cross population coming from crossing $O$. sativa $\mathrm{cv}$. IR58025B $\times$ O. meridionalis $(\mathrm{BC} 2 \mathrm{~F} 3)$ was evaluated under no moisture stress and in moisture stress conditions. This enabled the development of progenies with high yield potential under moisture stress. Grain yield of $\mathrm{BC} 2 \mathrm{~F} 3$ cross progenies was enhanced under moisture stress during reproductive stages [27]. Thus, O. meridionalis has favorable alleles for drought avoidance, and can be used in breeding for drought tolerance in cultigen rice. The relationship between root features, such as length, volume, and dry weight, and drought avoidance capability of O. meridionalis has also been examined [27]. It was found that root characteristics of $O$. meridionalis significantly contribute to its drought stress avoidance. Therefore, the drought avoidance genes along with the desirable root characteristics of some wild Oryza species could enable an acclimation strategy towards growing wild rice under unfavorable conditions or in water-limiting environments. 


\subsubsection{Disease Resistance}

Australian wild Oryza species have a high tolerance capability to the local pathogens of rice $[38,39]$. For instance, genes of rice-blast resistance existed in the ancestral population of Australian O. meridionalis [40]. Resistance genes from Australian O. rufipogon are considered a source of tungro virus tolerance [41]. Australian O. officinalis and O. australiensis harbor useful genes for bacterial blight, and brown planthopper (BPH) resistance [41,42]. Further, O. australiensis encodes a novel type of BPH18 gene which confers BPH resistance $[38,43]$. Durable blast resistance genes also exist in O. australiensis which have been incorporated into advanced breeding lines [44,45]. Moreover, O. australiensis genes such as BPH 10 and $\mathrm{BPH} 18$, confer insect pest resistance. Other genes such as PI 40, confer fungus resistance $[42,44,46]$. The disease tolerance capability of these wild Oryza species, may support their adaptation to paddy cultivation.

\subsection{Grain Quality of Australian Wild Oryza}

Grain quality is one of the most important factors which define the market price of rice and affect rice consumer preference [47]. Rice quality is mainly evaluated in terms of four aspects: milling, appearance, cooking/eating, and nutritional value [47-49]. The consumers' acceptance of each trait varies globally according to cuisine and culture [50]. Australian Oryza species are found to have excellent grain quality attributes which could contribute to their commercialization $[2,6,49]$.

\subsubsection{Grain Appearance}

Grain size and shape have different preferences among consumers throughout the world. For instance, long grain cultigen rice is consumed in Indian cuisines, medium grain rice cultivars are preferred in Southeast Asia, while short grains are preferred in many parts of north Asia [51,52]. The grain appearance (i.e., size and shape) of the wild Oryza species, including Australian O. rufipogon, O. australiensis and O. meridionalis has also been evaluated $[8,31]$. It was found that the grains of these species fall within the conventional ranges of domesticated rice (i.e., medium, short and long). This would suggest their acceptability to a wide range of consumers and their potential commercial value $[8,31]$.

\subsubsection{Grain Color}

Although the preferred color of commercial Oryza cultivars is pearl white, there is a growing interest in colored rice [31]. For instance, red cultigen rice is now being used in Japan in noodles, cakes and alcoholic beverages [53]. In addition, the colored wild American rice, Zizania, are used as gourmet food in soups and vegetable-based side dishes [30]. It has also been demonstrated that there is an association between rice grains color and their nutritional value [31]. The red, black, purple, and pink pigments in rice grains are due to the anthocyanins in the pericarp [54,55]. Anthocyanins possess antioxidant properties, which have significant human health advantages, including tumor cell growth suppression [56].

Several colors have been noticed in the wild Oryza grains [31]. For instance, the grain color of Australian wild Oryza varies from light red brown to dark brown which may represent potential antioxidant properties [31]. Fasahat et al. [57] evaluated the antioxidant properties of the wild Malaysian red rice (O. rufipogon L), as compared with domesticated rice from the Indica background. It was found that the antioxidant activity of wild Oryza was higher than that of cultigen rice. Therefore, wild Oryza species might have more commercial potential in a health food market and provide a new choice of product in the colored rice group.

\subsubsection{Cooking, Eating and Sensory Qualities}

Eating and cooking quality along with sensory properties are considered the most essential traits influencing consumer acceptance of rice. Eating and cooking quality are mostly evaluated by the physicochemical characteristics of the endosperm starch, namely, gel consistency, apparent amylose content, gelatinization temperature, and peak starch 
viscosity $[47,58]$. These attributes have been evaluated as a measure of the cooking and eating quality of Australian Oryza species [8,49]. It has been reported that Australian wild rice (Taxon $\mathrm{A}$ and $\mathrm{B}$ ) and $\mathrm{O}$. australiensis have high amylose contents and gelatinization temperatures, suggesting these species as a product in the health food market [8]. The morphology of starch particles and endosperm structure of Australian O. rufipogon and O. australiensis was also examined, and was found to be similar to that of O. sativa [59]. However, the protein structure was more obvious in O. rufipogon, and the starch granules were slightly smaller in $O$. australiensis.

Peak starch viscosity is another significant feature that is used to determine the swelling ability of starch granules when heated with water to cook rice [60]. It has been found that peak starch viscosity is significantly lower in some accessions of Australian Oryza species than most commercial varieties with Japonica backgrounds [1,6,49]. The values ranged from 130-221 rapid visco analysis (RVU) for O. meridionalis, 159-301 RVU for O. rufipogon, 221 RVU for O. sativa (SunRice White) and 469 RVU for O. sativa (SunRice premium long grain, Australia). The values obtained for Australian wild Oryza samples were within the range of some commercial rice samples with Japonica background, reflecting good eating and cooking proprieties.

Sensory properties, including texture, aroma and flavor, have been investigated for an Australian wild rice (Taxon B) [8]. Sensory properties of grain samples collected from Taxon B were compared with Asian commercial rice varieties (including medium and long grain, basmati, red basmati, and red rice) and with Canadian wild rice (Zizania palustris) [6]. Taxon $\mathrm{B}$ was found to be generally similar in sensory properties to red rice and red basmati, having a mild aroma and flavor. Taxon B had a firmer texture and required a longer cooking time. The sensory evaluation (texture, aroma and flavor) of Taxon B has indicated acceptable eating qualities, and that it has potential as a whole grain ingredient in gourmet foods [6]. Good sensory properties of wild rice (Taxon B) confirm the potential commercialization of these species. The overall physical attributes, cooking profiles and sensory properties suggest that Australian wild Oryza have a high potential for commercialization in the premium market.

\subsubsection{Grain Nutritional Quality}

Wild Oryza species exhibit a high nutritional profile, suggesting their potential as a highvalue product in premium markets $[61,62]$. O. meridionalis, O. rufipogon and O. australiensis were found to have a higher protein content than cultigen rice, suggesting a high nutritional value for human consumption [49]. Furthermore, high protein content in the endosperm is advantageous for the milling quality of the grain. It provides resilience and hardness during grain processing, reducing the grain breakage during milling [61]. Some essential nutrients have also been examined for Australian Oryza species. For instance, the study of Ishikawa et al. [63] shows that Australian O. meridionalis exhibits a high concentration of grain Zn compared with cultigen rice (O. sativa Japonica 'Nipponbare' and Indica 'IR36') and other wild rice species (O. rufipogon W630, O. glumaepatula W1169, and O. barthii W1152). Therefore, the high nutritional value of some wild Oryza species could underpin their potential commercial production.

\subsection{Grain Dormancy Breaking}

Wild Oryza species are known to have a stronger seed dormancy than cultigen rice, but the level of dormancy varies between species [33,64]. Seed dormancy-breaking approaches for two Australian Oryza species, O. rufipogon and O. meridionalis, involve germination after storage at alternating temperatures $\left(25 / 60^{\circ} \mathrm{C}\right)$, dry heat treatment $\left(>40{ }^{\circ} \mathrm{C}\right)$, palea and lemma (hull) removal, and the use of dormancy-breaking chemicals [33]. However, hull removal is a tedious process and risks damaging the seeds which may reduce germination. Hence, efficient and effective seed dormancy-breaking treatments or combinations of treatments have been developed to promote germination for two Australian Oryza species, O. meridionalis and O. australiensis, without the need to remove the hull [64]. These treat- 
ments include combining dry heat, with either gibberellic acid, $\mathrm{H}_{2} \mathrm{O}_{2}$, or $\mathrm{KNO}_{3}$ treatments (i.e., heat-treated seeds should be pre-soaked in $\mathrm{HNO}_{3}$ for the first $18 \mathrm{~h}$ before soaking in gibberellic acid $\mathrm{GA}_{3}$ or $\mathrm{H}_{2} \mathrm{O}_{2}$ for $18 \mathrm{~h}$ before sowing for germination). Since the seed dormancy of Australian Oryza species can efficiently be broken, it is no longer a barrier for its cultivation and subsequent commercialization.

\subsection{Indigenous Interest towards a Wildlife-Based Enterprise}

Australian Aboriginal people are the hosts of the oldest continuous culture on earth and possess deep ecological knowledge and spiritual connection to their land $[9,65]$. Their customary use of plant and animal resources over thousands of years has yielded an outstanding ecological knowledge of the value of natural resources, which has been inherited across generations $[9,65]$. In Australia, Aboriginal and Torres Strait Islander people, hereafter referred to as Indigenous Australians, are the landholders of nearly $78 \%$ of northern Australian land [9]. They also have knowledge of utilization of these natural resources through harvesting and processing of native plant species [9]. Globally, considerable attention has been raised to the potential for developing enterprises based on indigenous plant products to provide income, enhance livelihoods and maintain a strong incentive for land conservation $[9,65,66]$. This interest has been enshrined in international instruments such as the Nagoya Protocol which aims to protect the rights of indigenous people to benefit from commercial use of the native species about which they have indigenous knowledge and traditional cultural interests [66]. In Australia, Indigenous ecological knowledge has resulted in a significant commercial development of over fifteen native food species, including, desert raisins, macadamias and Kakadu Plum [65,67,68]. This has stimulated Indigenous interest for exploring further options for economic development through the commercialization of additional native plant species.

Indigenous Australians highly value the idea of a culture-based economy that involves their ecological knowledge and connection to their country [9,65]. Australian wild Oryza species provide an example of the potential for a culturally-identified plant product [2]. Their grains have been harvested and consumed as food by Aboriginal Australians for many generations $[69,70]$, and records are available of Australian native rice consumption in the 1970s [70], however, it is likely the use of native grains as a food dropped dramatically with the increasing availability of introduced staples such as flour and cultigen rice [71].

Furthermore, it is perceived that Indigenous cultural identification could enable the achievement of high market value of the wild Oryza grains. Pilot investigations indicated that tourists were prepared to pay the equivalent of 100 AUD per kilogram for grain samples of the wild Oryza species in northern Australia [2]. As a result, there has been considerable interest among Indigenous people in the commercialization of these valuable species through targeting markets that value culturally identified and ethically sourced native plant species $[10,68]$.

\section{Challenges to Commercialization of Australian Wild Oryza}

The major issues that could hinder the development of a rice industry based on wild Oryza species have been identified. These involve management and processing issues, undesirable wild behavior, and environmental concern.

\subsection{Management Issues}

\subsubsection{Lack of Agronomic Knowledge}

In the natural habitat, Australian Oryza species produce abundant grains [1]. The yield potential has been estimated to be $260 \mathrm{~kg} \mathrm{ha}^{-1}$ for $O$. meridionalis [72]. Hence, these species could be effectively exploited in their wild state without necessitating intensive cultivation. Unfortunately, wild harvest cannot provide a reliable and sustainable supply of the grains due to the unpredictable, interannual rainfall that restricts airboat access, along with crocodile risks [2]. Hence, cultivation in an easy and safe accessible environment is required as an initial step towards their commercial production. 
However, there is no information on optimum agronomic protocols for Australian wild Oryza species. Their yield under cultivation has not been determined [1]. Searches of online databases revealed no published literature on cultivation protocols in terms of optimum sowing and harvesting time, suitable soil conditions, optimum establishment methods, optimum fertilizer application, water demands, light requirements and optimum plant density and spacing patterns. It is expected that Australian Oryza species could be successfully cultivated when all environmental and management factors affecting their production are optimized.

\subsubsection{Seed Storage}

The ability of Australian Oryza species to remain viable in storage is unknown. Silcock et al. [73] reported that the germination of seeds of some tropical Australian grasses stored without refrigeration reduced slowly after two years and could be very low after five years. The longevity of Australian Oryza species under different storage conditions is unknown. High moisture and temperature are the limiting factors affecting grain quality attributes under storage [74,75]. Generally speaking, temperatures below $15^{\circ} \mathrm{C}$ and moistures below $9 \%$ could reduce the development of insects in cereal grains [74]. Similarly, the development of molds could be avoided by low temperatures $\left(<10^{\circ} \mathrm{C}\right)$, and by maintaining low moisture $(<13 \%)$ in cereal grains [74].

However, the key challenge for storing rice in northern Australian agriculture regions is the humidity [75]. Australian cultigen rice is generally harvested at $18-22 \%$ moisture (although this could be higher in the tropical, rainy seasons) to achieve the highest grain quality. However, seeds need to be stored with moisture content at or below 14\% [75]. If not managed appropriately, the high humidity and temperatures in tropical climates can easily lead to improperly stored grains and an unacceptable high final moisture content.

It is also not obvious whether laboratory germination tests can predict field establishment. Although increased storage time may lead to little change in germination percentage under laboratory conditions for some native grasses, field establishment percentage may decrease dramatically [73]. This effect may be even more of a problem when seeds are removed from florets [73]. Therefore, storage practices of the wild rice grains in northern Australia are challenging and need a well-developed infrastructure.

\subsubsection{Disease Control}

Australia is relatively safe from major diseases that are impacting rice; only a few rice diseases have been recorded [76]. One of the first announced diseases in Australian cultigen rice was the bacterial leaf blight, resulting in a substantial reduction in rice yield in northern Australia [77]. The occurrence of rice blast has also been reported in northern Australia [76]. Rice blast is the most damaging disease of rice internationally and detection of the disease in 2010 halted the cultigen rice industry in its tracks in northern Western Australia [76]. Therefore, the production of commercial rice varieties in northern Australia has achieved limited success due to some rice pathogens [39].

Although wild rice diseases are usually not destructive in natural stands, when cultivated in fields the impact of the same diseases on the wild rice species can be devastating [30]. For instance, fungal brown spot (Bipolaris oryzae) is one of the most prevalent and damaging diseases in cultivated American wild rice (Zizania) paddies [78]. Losses in Zizania production can be as high as $74 \%$ when the crop is infected by the fungus at the boot stage, and may cause average annual losses estimated at \$2.5 million [79]. Although Australian Oryza species show a wide range of resistance genes to the local rice pathogens in their natural habitats [38], this disease-resistance behavior needs to be examined under paddy cultivation.

\subsubsection{Weed and Pest Control}

Tropical floodplains of northern Australia are impacted by several exotic grass species [80,81]. Some weeds such as para grass (Urochloa mutica (Forssk.) T.Q.Nguyen), can 
produce high biomass and complex architecture which may cover and modify the seedbed of Oryza species, preventing seeds from receiving dormancy-breaking or germination cues [82]. Some weed control practices, such as burning during the dry season, can be applied to manage para grass [83]. However, burning itself contributes significantly to atmospheric pollution and may be discouraged as it will seriously affect the soil carbon/N balance. Hence, other effective weed management practices should be explored. Besides, the types of weed flora that might arise during the cultivation of the wild rice need to be investigated and managed.

Further, grains of Australian Oryza species are heavily consumed by some vertebrate pests such as native dusky plains rats and magpie geese [84]. Magpie geese (Anseranas semipalmata), are large waterbirds (up to $3.5 \mathrm{~kg}$ body weight) inhabiting Australia's northern floodplains in close proximity to wild rice populations [85]. Australian wild Oryza species are a key food source for these waterbirds [84]. One of the reasons for unsuccessful commercial rice trials in northern Australia was due to the partial destruction of the crops by magpie geese [86]. Therefore, establishing a wild rice industry in northern Australia could be threatened by weeds infestation and grain consumption by native pests.

\subsection{Post-Harvest Issues: Grain Processing}

Processing of Australian wild Oryza grains is difficult due to the structures around the grains. These include a very long awn (up to $100 \mathrm{~mm}$ long) (Figure 4), and palea and lemma (hull) that tightly enclose the grains [2]. The hull of Australian native rice taxa is harder than that of domesticated rice. Further, some Australian Oryza species have slender long grains, prone to breakage during processing [8]. Although long grains have small volumes, they also have a high hull percentage. The hull proportion is usually negatively correlated with milling quality [8]. Therefore, Australian wild Oryza could be expected to have lower milled rice recovery and be more difficult to mill as compared with commercial rice varieties.

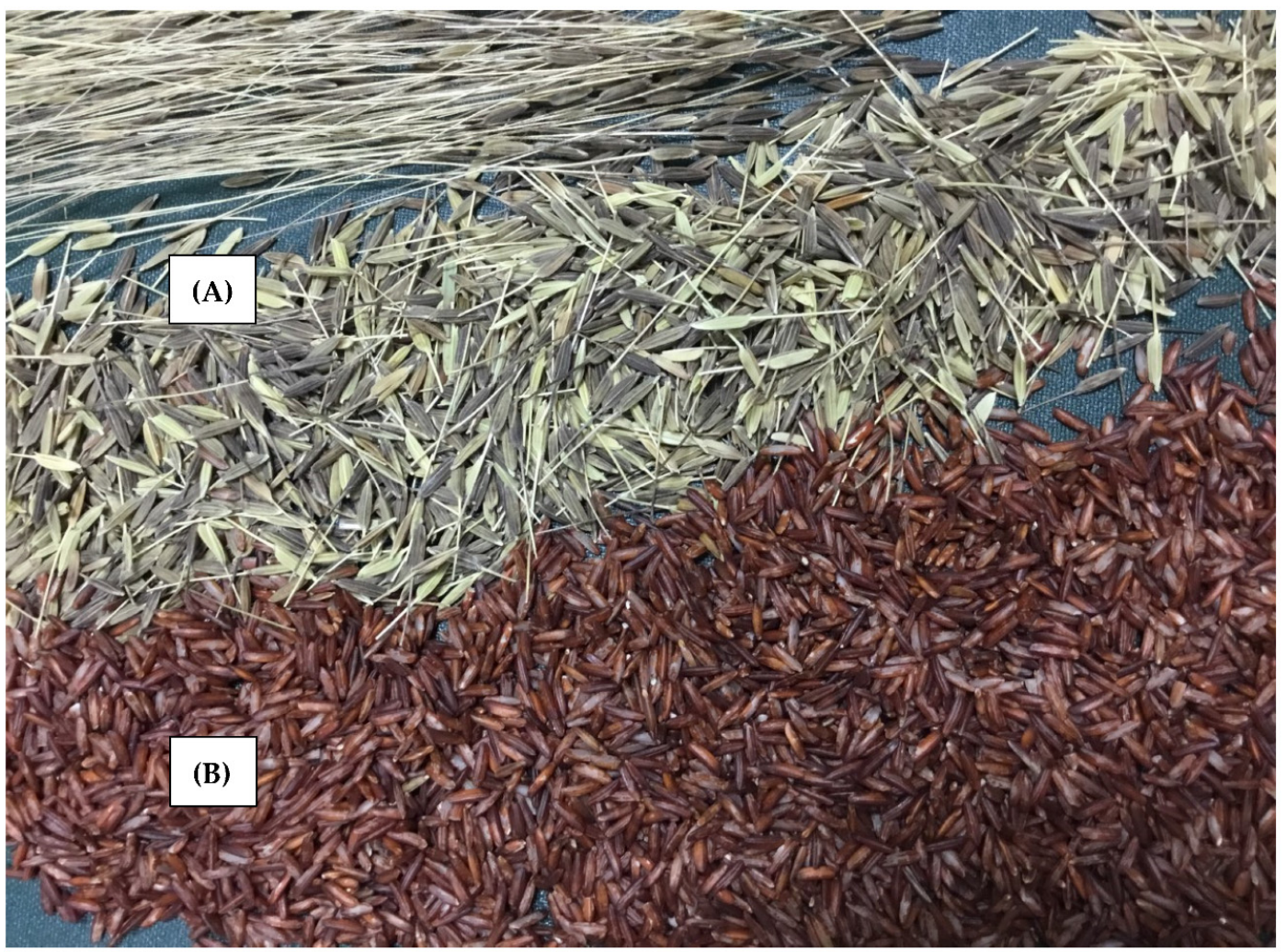

Figure 4. Australian wild Oryza meridionalis grains. (A) Grains with awns; (B) Processed grains without awns. 


\subsection{Undesirable Wild Characteristics: Shattering Behavior}

All wild Oryza species undergo shattering due to the ecological benefits of the gradual shed of seeds. Grains dispersed through shattering contribute to the continuity of the wild rice populations $[87,88]$. However, seed-shedding of wild Oryza is a major barrier for cultivation due to difficulties for harvest efficiency that shattering causes. Thus, wild harvest is a challenge due to the inherent shattering behavior of wild Oryza panicles and the different maturity stages of grains within one panicle. The tremendous expansion of wild American rice as a field crop has only occurred after the development of nonshattering varieties of wild rice [89]. Therefore, it is anticipated that efficient harvesting and sustainable development of any wild Oryza industry could only be achieved if this problem is overcome.

\subsection{Environmental Concern: Rainfall Variability}

Rainfall variation poses a range of threats for establishing a sustainable industry based on wild Oryza in northern Australia. Precipitation variability results in floods and drought conditions [90]. This may impact suitable habitats for the efficient cultivation of Australian Oryza species. In northern Australia, the climate is broadly classified as tropical monsoonal $[36,91,92]$. The monsoonal wet-dry tropics of northern Australia are typified by a summer wet season between January and April, when almost all the annual rainfall occurs (for example, an average of $1485 \mathrm{~mm}$ near Darwin in northern Australia), and a long winter dry season from May to October when almost no rainfalls. Although the occurrence of an annual wet season is reliable, the timing, duration and quantity of rainfall vary greatly between years. Tropical cyclones are frequent across northern Australia, bringing extreme rainfall. For some regions across tropical Australia, rainfall from tropical cyclones can on average contribute up to $30 \%$ to the annual rainfall amount [36,92]. It is unknown how sensitive Oryza species are to year-to-year weather conditions variability. The inter-annual change in yield associated with the inter-annual climate variability needs to be explored. Thus, unpredictable weather conditions should be modeled to support the successful establishment of the native rice industry in northern Australia.

\section{A Wild Rice Industry (Zizania): A Successful Case Study}

Reviewing the factors and pathways utilized for the successful commercial cultivation of American wild rice Zizania palustris could provide a guide for future research needs regarding the commercialization of Australian wild Oryza species. The annual Z. palustris is native to northern United States and southern Canada and is now being grown commercially in both countries [29,30]. Zizania palustris has large grains and high productivity, and its grains have been used as a traditional food by native Americans in North America for centuries [30]. Currently, it is cultivated mainly in California and Minnesota [93,94]. Cultivation of Z. palustris has mainly occurred due to the optimized agronomic knowledge and successful breeding of varieties with shattering resistance [95]. Zizania gained increasing popularity during the late 20th century among consumers because of its antioxidant components and health-promoting impacts [96], and it is now commonly available in supermarkets, restaurants and gourmet cuisine in North America and internationally. Its grains are now used as an ingredient in a variety of foods such as breakfast cereals, pancakes, soups, meat dishes, stuffing, muffins and cookies [30,97-99].

Oelke et al. [100] have reported the key approaches for the efficient establishment and production of Zizania under paddy cultivation which involve: (i) optimizing the agronomic practices that maximize plant performance and match plant's needs; (ii) identifying the optimum harvesting time along with applying innovative modifications to the harvesting equipment; (iii) modifying the post-harvest processing practices, resulting in the production of a commercially acceptable product; (iv) early recognition of the grains by consumerssince the 1960s_-as a gourmet food before cultivation commenced, so that it was already relatively high priced and in-demand; (v) recognizing high-value components within Zizania grains, increasing the demand for grains in the health-food market; (vi) engaging 
breeding programs, focusing on the non-shattering trait, and synchronizing maturity among tillers for efficient harvesting; and (vii) investing in the production and marketing of Zizania. The marketing of the cultivated Zizania was substantially supported by the long-term harvesting and marketing of the grain from the natural habitats. The name of the product was already well-known in the gourmet market due to the early establishment of the rice trade between Native Americans and colonizing settlers; thus the cultivated Zizania relied on the gourmet reputation of the grain [89].

As a result of these developments, commercial cultivation of Zizania started to fulfill the increased demand from the health-food market. Wild rice has exhibited changes from a local and gourmet commodity to an ingredient in international food markets. A packaged blend of wild American rice-long grain rice-and herbs was introduced in the early 1960s. Although one-third of wild rice sales are in the form of pure Zizania grains, a substantial percentage of the pure wild rice sales eventually reached the table as blends prepared by restaurants or retail consumers [89]. This product was widely accepted by consumers and was considered a significant development in expanding the market demand for wild rice. Although blends mainly have only about $15 \%$ wild rice grains, their increased sales have made them a prevalent factor in the wild rice market [89]. Innovation, market development, and advertising of blends by commercial firms have played an important role in introducing wild rice to consumers and was considered a significant development in expanding the market demand for wild rice [89]. If blends had not been introduced, the wild rice industry may not have achieved its current success [89].

\section{Conceptual Framework}

In northern Australia, several historical commercial rice trials with O. sativa occurred but most had limited success without any significant rice industry development. The reasons for these unsuccessful trials included poor agronomic protocols, failures in water management practices, unpredictable weather conditions, unsuitable rice varieties, rice pathogens, vertebrate pests invasion, and inconsistencies in markets [86]. Most importantly, crops of domesticated rice have been severely damaged by rice disease in northern Australia while surrounded by wild rice populations that appear disease resistant. Hence, Australian Oryza species are considered key resources for the potential industry based on wild Oryza species in northern Australia where these species naturally grow.

It is anticipated that commercial cultivation of these species will require overcoming a range of agronomic obstacles, modifying the undesirable wild traits, and managing some environmental variability. Through this review, we identify four key steps to establish a sustainable wild Oryza industry (Figure 5). These steps are based on experience and observations with unmanaged natural habitats of Australian Oryza species and reference guidelines from the adopted production protocols for the wild rice industry in north America. The framework is constructed on four fundamental ideas including; (i) optimization of agronomic protocols for commercial-scale production of wild Oryza; (ii) development of more efficient milling equipment to improve the grain milling quality; (iii) incorporation of plant breeding programs for developing improved varieties of wild rice; and (iv) addressing the essential role of ongoing partnerships between producers, breeders, researchers, government and private sectors, including Indigenous producers and enterprises for the sustainable commercial production of the wild Oryza species.

\subsection{Step I: Recommended Agronomic Protocols}

The first suggested step towards this industry involves identifying the best production protocols to cultivate the wild rice as a field crop (Figure 5). A suitable cultivation area would have to be accessible and would likely be associated with Indigenous communities. Land suitability is considered a crucial factor for improving the productivity of wild rice. For example, selection of weed-free sites could enable an optimization of the growing conditions. Coupled with this, there is a need for an enhanced understanding of soils, climate and plant needs for achieving high productivity and quality. Elucidation of interaction 
effects of agronomic practices, various soil types, and weather conditions are critically required for designing the best site-specific strategy.

Some critical decisions affecting Oryza establishment efficiency can be made before sowing such as seed viability (Figure 5). Selection and maintenance of high viable pure seeds are crucial for the success of any wild rice industry. Since the seed viability is influenced by the implemented storage techniques, storage practices that determine the seed viability of these species need to be well understood. This in turn will not only benefit their commercial production but will also increase the rate of their adoption. Therefore, establishing and financing effective high-quality storage infrastructure and procedures are expected to be essential for the success of the northern Australian wild rice industry.

Furthermore, there is a substantial need to explore the best agronomic protocols (Figure 5) for developing a wild rice industry. For example; (i) determining the practical sowing and harvesting times that coincide with adequate soil moisture and temperatures; (ii) evaluating the performance of the plant under different sowing methods such as transplanting, wet-seeding, and dry-seeding conditions, something that could be followed by identifying issues that could affect uniform, reliable and cost-effective wild rice establishment; (iii) determining the optimum population density and spacing levels that maximize the grain quality and yield potential; (iv) studying the effect of using shading material on the degree of yield decline of wild rice compared with full sunlight conditions; (v) developing nutrient management systems that avoid yield decline and, most importantly, trials that should involve organic production of the wild rice without applying chemical fertilizers or herbicides; (vi) investigating suitable irrigation schedules (timing and amounts) to improve understanding of wild rice response to different water regimes, most importantly how to reduce the amount of water required to cultivate the wild rice and how to increase the efficiency of water use for grain production; (vii) developing effective and sustainable control techniques for the major weeds, pests and diseases that will arise under paddy cultivation of the wild rice, with particular emphasis on the development of integrated management programs and herbicide resistance protocols; (viii) avoiding intensive wild rice cultivation by adopting crop rotation with other non-cereal crops; and (ix) modelling the responses of the wild rice to climate variability and rice field environment, particularly in response to varying inter-annual rainfall intensity. Crop models are potentially powerful tools in identifying critical areas for research and pathways for increasing yield potential.

In addition, developing the human resources for this industry needs substantial consideration. This can be achieved through the selection of appropriate business models and value addition, producer education, community awareness, extension and information technology methods, technological skills development and professional development. If any of these practices are compromised, then this may have ongoing management and commercial implications, and therefore can determine the success or failure of a developing wild rice industry.

There is a particular need for research into the impact of agronomic management on the grain quality attributes of wild rice, such as milling quality, grain appearance, and cooking properties. Investigating how specific accessions of the wild rice interact with agronomic practices will provide better recommendations to wild rice producers, reducing the variability in grain quality found within the rice industry. There is consequently no place for wild rice cultivars with major grain quality defects even if yield potential is increased. Overemphasis on grain quality in the early stages could limit the progress of developing higher-yielding improved cultivars of wild rice; however, the milling and cooking characteristics of the final product must match the requirements of target markets. 


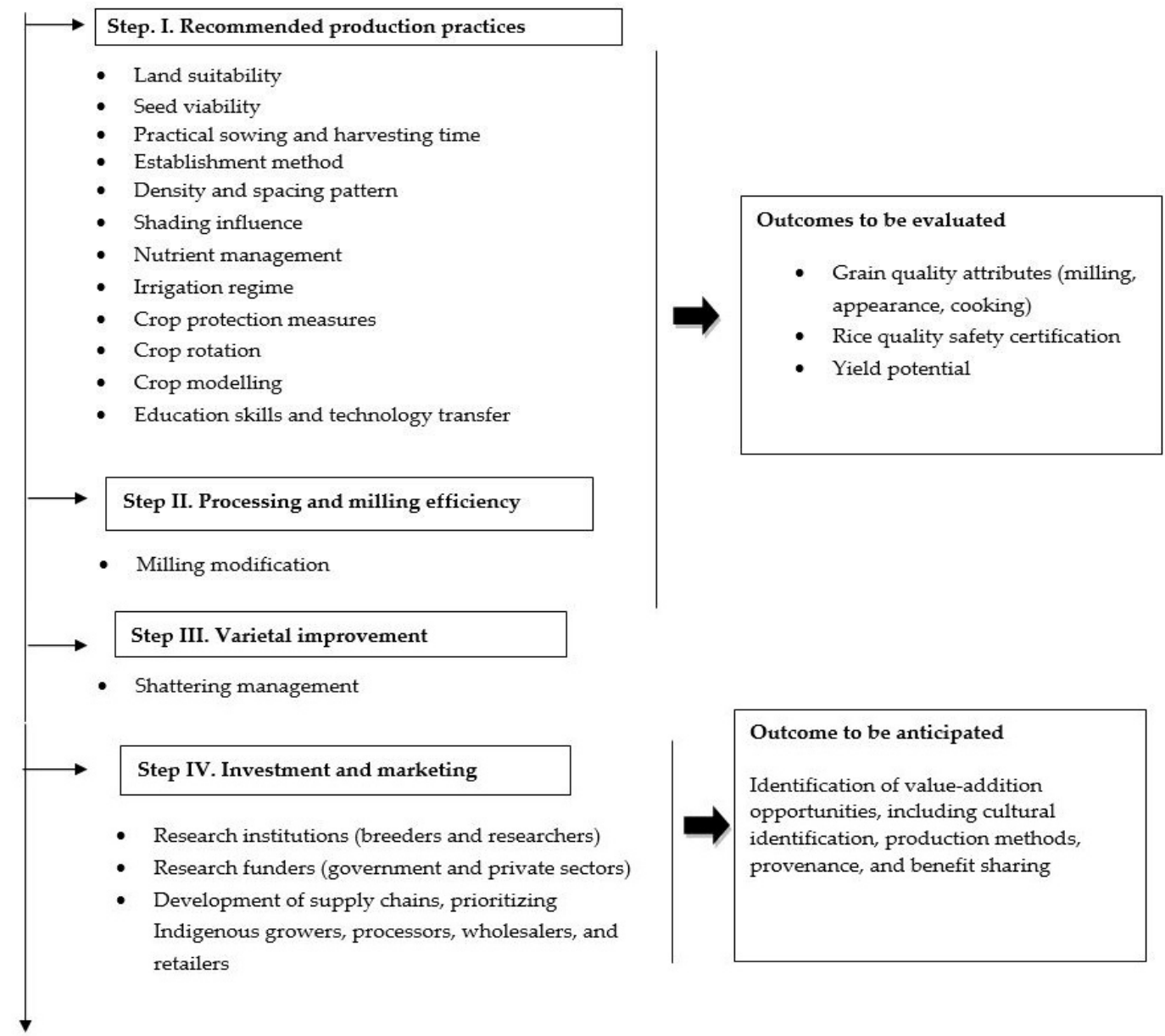

A sustainable wild Oryza industry

Figure 5. A conceptual framework for the development of a sustainable wild rice industry in northern Australia.

\subsection{Step II: Processing and Milling Efficiency}

Efficient processing of the wild Oryza grains is harder than any other cereal grains due to the structures around the grains as highlighted in Section 3.2 of this review. For American wild rice, efficient grain processing results in the development of commercially acceptable wild rice grains along with a unique flavor that distinguishes wild rice grains from other cereal grains [101]. For effective processing of Australian wild Oryza grains, awn removal and milling equipment need to be modified and improved (Figure 5). Achieving highquality wild rice production is expected to be the outcome of optimal growing conditions and high milling efficiency.

\subsection{Step III: Varietal Improvement}

The development of improved varieties of wild Oryza species may be required for the success of this industry in some contexts and over the long term (Figure 5). The study of Yu et al. [3] revealed the tendency of efficient enhancement of various traits in O. alta, a wild allotetraploid rice, through an efficient transformation and genome editing system. This could enable the production of high-quality genotypes and reduction in the time required for domestication to take place. Further, all wild Oryza species are extremely prone to shattering. Hence, breeding programs should target the development 
of shattering-resistant cultivars of wild rice. For instance, Australian Oryza species, such as O. meridionalis and O. rufipogon, are genetically similar to O. sativa [1]. Also, O. meridionalis has been found to have high crossability with O. sativa [102,103]. This similarity coupled with modern advances in rice genomics could expand the wild rice industry through the production of shattering-resistant cultivars. The incorporation of modern molecular genetics approaches will eventually improve the breeding ability of wild Oryza species, resulting in the production of improved varieties of wild rice that are more resistant to seed shattering. For American wild rice, its shattering behavior contributed to yield losses that ranged from $26 \%$ to more than $40 \%$ [95]. However, plant breeding programs enabled the development of non-shattering cultivars of American wild rice with yields of $1680 \mathrm{~kg} \mathrm{ha}^{-1}$, compared to 168 to $224 \mathrm{~kg} \mathrm{ha}^{-1}$ yielded from shattering varieties [89,95]. The breeding of Zizania with some seed-shattering resistance varieties has enabled growers to harvest fields in one pass, and substantially increase yields. For sustainable production of wild Oryza species, breeding programs should also target the development of wild rice cultivars that are highly adapted to changing climate. Therefore, the engagement of breeding programs needs to be considered and implemented for a successful and sustainable wild rice industry.

\subsection{Step IV: Investment and Marketing}

There is a need to identify sources of investment funding (Figure 5). Research funds from government and private sectors along with the cooperation of researchers could contribute to the development of improved varieties of wild Oryza species. The funding of a breeding program would be a significant development in their cultivation. The success of these practices will attract considerable attention from local growers and investors. It is essential to establish an integrated system that connects growers with supply chain, government and other research organizations. This will ensure an excellent production of the wild rice grown under paddy conditions followed by excellent processing and marketing within and outside of the country. Marketing of these species may be aided by its preliminary recognition as a gourmet food along with their cultural identification through grains harvested from natural stands by Indigenous Australians. Grains produced and marketed by Indigenous producers will always have higher economic value in some markets than grains grown under broadacre conditions. The likely additional market values of native rice grains produced by Indigenous growers may include cultural identification, provenance and fair-trade production values (e.g., Indigenous employment and benefit sharing). Therefore, marketing of Australian native rice grains could be partially supported by their Indigenous cultural value. It is also imperative to specifically direct efforts in designing and implementing campaigns to promote the functional and image attributes of these valuable species, attributes such as good physicochemical properties, informative labeling, and safety certification. This needs to be supported by an efficient distribution system that ensures the availability of wild Oryza brands in niche markets and sales outlets across Australia.

Recently, there has been a strong interest in the commercialization of Australian Oryza species through investments from different Australian government agencies, universities and other research institutions, as well as commitments from Indigenous organizations and enterprises. These sectors are willing to invest in the production and marketing of these species as wild relatives of cultivated rice and a potential source of genetic resources and information. Many First Nations North Americans benefit from Zizania enterprises [30,95], and this is a key goal for many Australian native rice commercialization projects [2].

\section{Conclusions}

We provide a strategy for the commercial production of wild Oryza species that are native to northern Australia. The suggested procedures for a wild rice industry in northern Australia are also applicable for any other wild Oryza species. Australian wild Oryza species produce a visually appealing, nutritious and palatable grain for gourmet markets. Australian Oryza species have excellent grain quality attributes, suggesting a high commercial 
potential. They also exhibit tolerance for a range of biotic and abiotic stresses as they are from environments that are often harsh. Further, there is a strong interest in developing an industry based on wild Oryza species in northern Australia where these species naturally grow. As a result, wild Oryza species are considered excellent candidates for a niche wild rice industry. The success of this industry could provide economic development for Indigenous Australians. However, this overview has highlighted a lack of knowledge relating to the commercial production of these valued species in terms of their optimum growing conditions, suitable management practices, along with other issues.

We identify some undesirable wild traits of wild Oryza which are obstacles for commercial production of these species, such as shattering. Efforts from researchers will be essential to overcome this issue if wild rice is to be cultivated under paddy conditions. Breeding of wild Oryza with non-shattering cultivars is an option. In addition, advanced technology such as genome editing also provides a great opportunity for overcoming undesirable traits in the wild Oryza species. The development of improved varieties through breeding programs and emerging technologies are probably necessary for the long-term success of any wild rice industry. Ongoing partnerships between breeders, researchers, and producers will have a substantial influence on the success of this industry.

A conceptual framework is suggested for building an industry based on wild Oryza species. It provides a visual representation of how different practices could influence the cultivation and commercialization process of wild Oryza species. We conclude that research in sustainable wild rice production should be given attention in Australia to ensure continuous generation of knowledge and an understanding of the potential methods that can contribute to sustainable and reliable wild rice cultivation. Targeted breeding programs, in combination with agronomic research, should be used to address this wild rice industry. An integrated system is needed that connects growers with supply chains, government and other institutional stakeholders, and ensures that excellent wild rice production is supported by excellent processing and marketing within, and outside of, Australia.

Author Contributions: G.A. wrote the manuscript, and prepared Figures 3 and 5. S.M.B. prepared Figure $1 \mathrm{~B}$ of the manuscript. S.M.B., P.W. and L.T.M.H. critically revised the manuscript and provided feedback. All authors contributed significantly to the conceptualization and preparation of the manuscript and approved the submitted version. All authors have read and agreed to the published version of the manuscript.

Funding: Open access funding was provided by Charles Darwin University, Darwin, Australia. GA was supported by Research Training Program (RTP) Scholarship provided by the Commonwealth Government of Australia.

Data Availability Statement: Not applicable.

Acknowledgments: This review paper was supported by the Australian Research Training Programme (RTP)-International Stipend and Tuition Fees PhD Scholarship provided by the Commonwealth Government of Australia. The research is also associated with a larger project funded by the Future Food Systems Cooperative Research Centre, Australia. We thank Tony Asis for his early contribution in suggesting some ideas to develop the manuscript. We also thank Lynette Kenyon and Graham Kenyon for discussion about marketing and enterprise development. We thank the three anonymous reviewers for their valuable comments that significantly enhanced the quality of the manuscript.

Conflicts of Interest: The authors declare no conflict of interest.

\section{References}

1. Henry, R. Australian wild rice populations: A key resource for global food security. Front. Plant Sci. 2019, 10, 1354. [CrossRef] [PubMed]

2. Wurm, P.P.; Bellairs, S. North Australian Native Rice: Market Evaluation of a Potential New Wild Food Enterprise; Publication No. 18/032; AgriFutures: Wagga Wagga, NSW, Australia, 2018.

3. Yu, H.; Lin, T.; Meng, X.; Du, H.; Zhang, J.; Liu, G.; Chen, M.; Jing, Y.; Kou, L.; Li, X. A route to de novo domestication of wild allotetraploid rice. Cell 2021, 184, 1156-1170.e14. [CrossRef] [PubMed] 
4. $\quad$ Henry, R.J.; Rice, N.; Waters, D.L.; Kasem, S.; Ishikawa, R.; Hao, Y.; Dillon, S.; Crayn, D.; Wing, R.; Vaughan, D. Australian Oryza: Utility and conservation. Rice 2010, 3, 235-241. [CrossRef]

5. Nguyen, H.T.T.; Das Bhowmik, S.; Long, H.; Cheng, Y.; Mundree, S.; Hoang, L.T.M. Rapid Accumulation of Proline Enhances Salinity Tolerance in Australian Wild Rice Oryza australiensis Domin. Plants 2021, 10, 2044. [CrossRef]

6. Tikapunya, T.; Fox, G.; Furtado, A.; Henry, R. Grain physical characteristic of the Australian wild rices. Plant Genet. Resour. 2017, 15, 409. [CrossRef]

7. Tikapunya, T.; Zou, W.; Yu, W.; Powell, P.O.; Fox, G.P.; Furtado, A.; Henry, R.J.; Gilbert, R.G. Molecular structures and properties of starches of Australian wild rice. Carbohydr. Polym. 2017, 172, 213-222. [CrossRef] [PubMed]

8. Tikapunya, T.; Henry, R.J.; Smyth, H. Evaluating the sensory properties of unpolished Australian wild rice. Food Res. Int. 2018, 103, 406-414. [CrossRef] [PubMed]

9. Jarvis, D.; Maclean, K.; Woodward, E. The Australian Indigenous-led bush products sector: Insights from the literature and recommendations for the future. Ambio 2021, 51, 226-240. [CrossRef] [PubMed]

10. Zander, K.K.; Austin, B.J.; Garnett, S.T. Indigenous peoples' interest in wildlife-based enterprises in the Northern Territory, Australia. Human Ecol. 2014, 42, 115-126. [CrossRef]

11. Jacquemin, J.; Bhatia, D.; Singh, K.; Wing, R.A. The International Oryza Map Alignment Project: Development of a genus-wide comparative genomics platform to help solve the 9 billion-people question. Curr. Opin. Plant Biol. 2013, 16, 147-156. [CrossRef]

12. Vaughan, D.A. The Wild Relatives of Rice: A Genetic Resources Handbook; International Rice Research Institute: Manila, Philippines, 1994.

13. Vaughan, D.A.; Morishima, H.; Kadowaki, K. Diversity in the Oryza genus. Curr. Opin. Plant Biol. 2003, 6, 139-146. [CrossRef]

14. Atwell, B.J.; Wang, H.; Scafaro, A.P. Could abiotic stress tolerance in wild relatives of rice be used to improve Oryza sativa? Plant Sci. 2014, 215, 48-58. [CrossRef]

15. Australia's Virtual Herbarium, Council of Heads of Australasian Herbaria. Available online: http://www.chah.gov.au/avh (accessed on 12 December 2021).

16. Ng, N.; Hawkes, J.; Williams, J.; Chang, T. The recognition of a new species of rice (Oryza) from Australia. Bot. J. Linn. Soc. 1981, 82, 327-330. [CrossRef]

17. Lam, D.T.; Ichitani, K.; Henry, R.J.; Ishikawa, R. Molecular and Morphological Divergence of Australian Wild Rice. Plants 2020, 9 , 224. [CrossRef] [PubMed]

18. Sotowa, M.; Ootsuka, K.; Kobayashi, Y.; Hao, Y.; Tanaka, K.; Ichitani, K.; Flowers, J.M.; Purugganan, M.D.; Nakamura, I.; Sato, Y.-I. Molecular relationships between Australian annual wild rice, Oryza meridionalis, and two related perennial forms. Rice 2013, 6, 26. [CrossRef] [PubMed]

19. Brozynska, M.; Copetti, D.; Furtado, A.; Wing, R.A.; Crayn, D.; Fox, G.; Ishikawa, R.; Henry, R.J. Sequencing of Australian wild rice genomes reveals ancestral relationships with domesticated rice. Plant Biotechnol. J. 2017, 15, 765-774. [CrossRef] [PubMed]

20. Chivers, I.; Aldous, D. Reproductive and vegetative responses of different accessions of Microlaena stipoides (Labill.) R. Br. to nitrogen applications and supplementary irrigation in southern Australia. Rangel. J. 2005, 27, 151-157. [CrossRef]

21. Australian Plant Census. Available online: http://www.chah.gov.au/apc/index.html (accessed on 24 March 2021).

22. Johnston, W.; Clifton, C.; Cole, I.; Koen, T.; Mitchell, M.; Waterhouse, D. Low input grasses useful in limiting environments (LIGULE). Aust. J. Agric. Res. 1999, 50, 29-54. [CrossRef]

23. Meyer, R.S.; DuVal, A.E.; Jensen, H.R. Patterns and processes in crop domestication: An historical review and quantitative analysis of 203 global food crops. New Phytol. 2012, 196, 29-48. [CrossRef] [PubMed]

24. Shapter, F.M.; Cross, M.; Ablett, G.; Malory, S.; Chivers, I.H.; King, G.J.; Henry, R.J. High-throughput sequencing and mutagenesis to accelerate the domestication of Microlaena stipoides as a new food crop. PLoS ONE 2013, 8, e82641. [CrossRef] [PubMed]

25. Waters, D.L.; Nock, C.J.; Ishikawa, R.; Rice, N.; Henry, R.J. Chloroplast genome sequence confirms distinctness of Australian and Asian wild rice. Ecol. Evol. 2012, 2, 211-217. [CrossRef]

26. Moner, A.M.; Furtado, A.; Chivers, I.; Fox, G.; Crayn, D.; Henry, R.J. Diversity and evolution of rice progenitors in Australia. Ecol. Evol. 2018, 8, 4360-4366. [CrossRef] [PubMed]

27. Gouda, P.K.; Kumar Varma, C.M.; Saikumar, S.; Kiran, B.; Shenoy, V.; Shashidhar, H. Direct selection for grain yield under moisture stress in Oryza sativa cv. IR58025B $\times$ Oryza meridionalis population. Crop Sci. 2012, 52, 644-653. [CrossRef]

28. Yichie, Y.; Brien, C.; Berger, B.; Roberts, T.H.; Atwell, B.J. Salinity tolerance in Australian wild Oryza species varies widely and matches that observed in O. sativa. Rice 2018, 11, 66. [CrossRef] [PubMed]

29. Yan, N.; Du, Y.; Liu, X.; Chu, M.; Shi, J.; Zhang, H.; Liu, Y.; Zhang, Z. A comparative UHPLC-QqQ-MS-based metabolomics approach for evaluating Chinese and North American wild rice. Food Chem. 2019, 275, 618-627. [CrossRef] [PubMed]

30. Oelke, E.A. Wild Rice: Domestication of a Native North American Genus: New crops. In New Crops; Janick, J., Simon, J., Eds.; Wiley: New York, NY, USA, 1993; pp. 235-243.

31. Kasem, S.; Waters, D.L.; Rice, N.; Shapter, F.M.; Henry, R.J. Whole grain morphology of Australian rice species. Plant Genet. Resour. 2010, 8, 74-81. [CrossRef]

32. Cole, I.; Johnston, W. Seed production of Australian native grass cultivars: An overview of current information and future research needs. Aust. J. Exp. Agric. 2006, 46, 361-373. [CrossRef] 
33. Bellairs, S.M.; Wurm, P.A.S.; Kernich, B. Temperature affects the dormancy and germination of sympatric annual (Oryza meridionalis) and perennial (O. rufipogon) native Australian rices (Poaceae) and influences their emergence in introduced para grass (Urochloa mutica) swards. Aust. J.Bot. 2015, 63, 687-695. [CrossRef]

34. Scafaro, A.P.; Haynes, P.A.; Atwell, B.J. Physiological and molecular changes in Oryza meridionalis Ng., a heat-tolerant species of wild rice. J. Exp. Bot. 2010, 61, 191-202. [CrossRef] [PubMed]

35. Scafaro, A.P.; Gallé, A.; Van Rie, J.; Carmo-Silva, E.; Salvucci, M.E.; Atwell, B.J. Heat tolerance in a wild Oryza species is attributed to maintenance of Rubisco activation by a thermally stable Rubisco activase ortholog. New Phytol. 2016, 211, 899-911. [CrossRef] [PubMed]

36. Australian Government Bureau of Meteorology. Available online: http://www.bom.gov.au/climate/averages/tables/cw_014015 .shtml (accessed on 21 May 2021).

37. Hoang, T.; Tran, T.; Nguyen, T.; Williams, B.; Wurm, P.; Bellairs, S.; Mundree, S. Improvement of Salinity Stress Tolerance in Rice: Challenges and Opportunities. Agronomy 2016, 6, 54. [CrossRef]

38. Huang, D.; Qiu, Y.; Zhang, Y.; Huang, F.; Meng, J.; Wei, S.; Li, R.; Chen, B. Fine mapping and characterization of BPH27, a brown planthopper resistance gene from wild rice (Oryza rufipogon Griff.). Theor. Appl. Genet. 2013, 126, 219-229. [CrossRef] [PubMed]

39. Khemmuk, W.; Shivas, R.G.; Henry, R.J.; Geering, A.D. Fungi associated with foliar diseases of wild and cultivated rice (Oryza spp.) in northern Queensland. Australas. Plant Pathol. 2016, 45, 297-308. [CrossRef]

40. Yoshida, K.; Miyashita, N.T. DNA polymorphism in the blast disease resistance gene Pita of the wild rice Oryza rufipogon and its related species. Genes Genet. Syst. 2009, 84, 121-136. [CrossRef]

41. Brar, D.; Khush, G. Alien introgression in rice. In Oryza: From Molecule to Plant; Sasaki, T., Moore, G., Eds.; Springer: Dordrecht, The Netherlands, 1997; pp. 35-47.

42. Jena, K.; Jeung, J.; Lee, J.; Choi, H.; Brar, D. High-resolution mapping of a new brown planthopper (BPH) resistance gene, Bph18 $(\mathrm{t})$, and marker-assisted selection for BPH resistance in rice (Oryza sativa L.). Theor. Appl. Genet. 2006, 112, 288-297. [CrossRef]

43. Ji, H.; Kim, S.-R.; Kim, Y.-H.; Suh, J.-P.; Park, H.-M.; Sreenivasulu, N.; Misra, G.; Kim, S.-M.; Hechanova, S.L.; Kim, H. Map-based cloning and characterization of the BPH18 gene from wild rice conferring resistance to brown planthopper (BPH) insect pest. Sci. Rep. 2016, 6, 34376. [CrossRef] [PubMed]

44. Jeung, J.; Kim, B.; Cho, Y.; Han, S.; Moon, H.; Lee, Y.; Jena, K. A novel gene, Pi40 (t), linked to the DNA markers derived from NBS-LRR motifs confers broad spectrum of blast resistance in rice. Theor. Appl. Genet. 2007, 115, 1163-1177. [CrossRef] [PubMed]

45. Suh, J.; Roh, J.; Cho, Y.; Han, S.; Kim, Y.; Jena, K. The Pi40 gene for durable resistance to rice blast and molecular analysis of Pi40-advanced backcross breeding lines. Phytopathology 2009, 99, 243-250. [CrossRef]

46. Ishii, T.; Brar, D.; Multani, D.; Khush, G. Molecular tagging of genes for brown planthopper resistance and earliness introgressed from Oryza australiensis into cultivated rice, O. sativa. Genome 1994, 37, 217-221. [CrossRef] [PubMed]

47. Yi, D.; Maike, W.; Yi, S.; Xiaoli, S.; Dianxing, W.; Wenjian, S. Physiochemical Properties of Resistant Starch and Its Enhancement Approaches in Rice. Rice Sci. 2021, 28, 31-42. [CrossRef]

48. Bao, J. Toward understanding the genetic and molecular bases of the eating and cooking qualities of rice. Cereal Foods World 2012, 57, 148-156. [CrossRef]

49. Kasem, S.; Waters, D.L.; Ward, R.; Rice, N.; Henry, R.J. Wild Oryza grain physico-chemical properties. Trop. Plant Biol. 2014, 7, 13-18. [CrossRef]

50. Lyon, B.G.; Champagne, E.T.; Vinyard, B.T.; Windham, W.R. Sensory and instrumental relationships of texture of cooked rice from selected cultivars and postharvest handling practices. Cereal Chem. 2000, 77, 64-69. [CrossRef]

51. Cruz, N.D.; Khush, G. Rice grain quality evaluation procedures. In Aromatic Rices; Singh, R., Khush, G., Eds.; Oxford \& IBH Publishing: New Delhi, India, 2000; Volume 3, pp. 15-28.

52. Wrigley, C. Encyclopedia of grain science. In Encyclopedia of Grain Science; Wrigley, C., Croke, H., Walker, C., Eds.; Elsevier: Amsterdam, The Netherlands, 2004; pp. 187-200.

53. Itani, T. History and recent trends of red rice in Japan. Jpn. J. Crop Sci. 2004, 73, 137-147. [CrossRef]

54. Patindol, J.; Flowers, A.; Kuo, M.-I.; Wang, Y.-J.; Gealy, D. Comparison of physicochemical properties and starch structure of red rice and cultivated rice. J. Agric. Food Chem. 2006, 54, 2712-2718. [CrossRef] [PubMed]

55. Abdel-Aal, E.-S.M.; Young, J.C.; Rabalski, I. Anthocyanin composition in black, blue, pink, purple, and red cereal grains. J. Agric. Food Chem. 2006, 54, 4696-4704. [CrossRef] [PubMed]

56. Koide, T.; Kamei, H.; Hashimoto, Y.; Kojima, T.; Hasegawa, M. Antitumor effect of hydrolyzed anthocyanin from grape rinds and red rice. Cancer Biother. Radiopharm. 1996, 11, 273-277. [CrossRef]

57. Fasahat, P.; Muhammad, K.; Abdullah, A.; Ratnam, W. Proximate nutritional composition and antioxidant properties of 'Oryza rufipogon', a wild rice collected from Malaysia compared to cultivated rice, MR219. Aust. J. Crop Sci. 2012, 6, $1502-1507$.

58. Zhu, D.; Zhang, H.; Guo, B.; Xu, K.; Dai, Q.; Wei, C.; Zhou, G.; Huo, Z. Physicochemical properties of indica-japonica hybrid rice starch from Chinese varieties. Food Hydrocoll. 2017, 63, 356-363. [CrossRef]

59. Shapter, F.M.; Henry, R.; Lee, L. Endosperm and starch granule morphology in wild cereal relatives. Plant Genet. Resour. 2008, 6, 85. [CrossRef]

60. Wani, A.A.; Singh, P.; Shah, M.A.; Schweiggert-Weisz, U.; Gul, K.; Wani, I.A. Rice starch diversity: Effects on structural, morphological, thermal, and physicochemical properties-A review. Compr. Rev. Food Sci. Food Saf. 2012, 11, 417-436. [CrossRef] 
61. Zhou, C.; Huang, Y.; Jia, B.; Wang, Y.; Wang, Y.; Xu, Q.; Li, R.; Wang, S.; Dou, F. Effects of cultivar, nitrogen rate, and planting density on rice-grain quality. Agronomy 2018, 8, 246. [CrossRef]

62. Nadeem, F.; Farooq, M. Application of micronutrients in rice-wheat cropping system of south Asia. Rice Sci. 2019, 26, 356-371. [CrossRef]

63. Ishikawa, R.; Iwata, M.; Taniko, K.; Monden, G.; Miyazaki, N.; Orn, C.; Tsujimura, Y.; Yoshida, S.; Ma, J.F.; Ishii, T. Detection of quantitative trait loci controlling grain zinc concentration using Australian wild rice, Oryza meridionalis, a potential genetic resource for biofortification of rice. PLOS ONE 2017, 12, e0187224.

64. Timple, S.E.; Hay, F.R.; Mercado, M.; Fatima, O.; Borromeo, T.H. Response of intact seeds of wild rice (Oryza) species to dry heat treatment and dormancy-breaking chemicals. Seed Sci. Technol. 2018, 46, 157-173. [CrossRef]

65. Gorman, J.; Pearson, D.; Wurm, P. Old ways, new ways-Scaling up from customary use of plant products to commercial harvest taking a multifunctional, landscape approach. Land 2020, 9, 171. [CrossRef]

66. Buck, M.; Hamilton, C. The Nagoya Protocol on access to genetic resources and the fair and equitable sharing of benefits arising from their utilization to the Convention on Biological Diversity. Rev. Eur. Community Int. Environ. Law 2011, 20, 47-61. [CrossRef]

67. Gorman, J.T.; Wurm, P.A.; Vemuri, S.; Brady, C.; Sultanbawa, Y. Kakadu Plum (Terminalia ferdinandiana) as a Sustainable Indigenous Agribusiness. Econ. Bot. 2019, 74, 74-91. [CrossRef]

68. Woodward, E.; Jarvis, D.; Maclean, K. The Traditional Owner-Led Bush Products Sector: An Overview; CSIRO: Canberra, Australia, 2019.

69. Fujiwara, H. Logic Testing and Design for Testability; MIT Press: Cambridge, MA, USA, 1985; p. 29.

70. Fujiwara, H.; Jones, R.; Brockwell, C.J. Plant opals (phytoliths) in Kakadu archaeological sites: A preliminary report. In Archaeological Research in Kakadu National Park; Jones, R., Ed.; Australian National Parks and Wildlife Service: Canberra, ACT, Australia, 1985; pp. 155-164.

71. Russell-Smith, J.; Lucas, D.; Gapindi, M.; Gunbunuka, B.; Kapirigi, N.; Namingum, G.; Lucas, K.; Giuliani, P.; Chaloupka, G. Aboriginal resource utilization and fire management practice in western Arnhem Land, monsoonal northern Australia: Notes for prehistory, lessons for the future. Human Ecol. 1997, 25, 159-195. [CrossRef]

72. Wurm, P.A. The Population Ecology of Oryza meridionalis Ng on the South Alligator River Floodplain, Kakadu National Park, Monsoonal Australia. Ph.D. Thesis, Northern Territory University, Darwin, NT, Australia, 1998.

73. Silcock, R.; Williams, L.; Smith, F. Quality and storage characteristics of the seeds of important native pasture species in south-west Queensland. Rangel. J. 1990, 12, 14-20. [CrossRef]

74. Befikadu, D. Factors affecting quality of grain stored in Ethiopian traditional storage structures and opportunities for improvement. Int. J. Sci. Basic. Appl. Res. 2014, 18, 235-257.

75. Bellairs, S.M.; Caswell, M.J. Seed viability of native grasses is important when revegetating native wildlife habitat. North Territ. Nat. 2016, 27, 36.

76. Bajwa, A.A.; Chauhan, B.S. Rice production in Australia. In Rice Production Worldwide; Mahajan, G., Chauhan, B.S., Jabran, K., Eds.; Springer: Cham, Switzerland, 2017; pp. 169-184.

77. Aldrick, S.J.; Buddenhagen, I.; Reddy, A. The occurrence of bacterial leaf blight in wild and cultivated rice in Northern Australia. Austr. J. Agric. Res. 1973, 24, 219-227. [CrossRef]

78. Nyvall, R.; Percich, J.; Porter, R.; Brantner, J. Comparison of fungal brown spot severity to incidence of seedborne Bipolaris oryzae, B. sorokiniana and infected floral sites on cultivated wild rice. In Minnesota Wild Rice Research; University of Minnesota: Minneapolis, MN, USA, 1995; pp. 68-70.

79. Johnson, D.R.; Percich, J.A. Wild rice domestication, fungal brown spot disease, and the future of commercial production in Minnesota. Plant Dis. 1992, 76, 1193-1198. [CrossRef]

80. Ferdinands, K.; Beggs, K.; Whitehead, P. Biodiversity and invasive grass species: Multiple-use or monoculture? Wildl. Res. 2005, 32, 447-457. [CrossRef]

81. Boyden, J.; Wurm, P.; Joyce, K.E.; Boggs, G. A spatial vulnerability assessment of monsoonal wetland habitats to para grass invasion in Kakadu National Park, northern Australia. Int. J. Appl. Earth Obs. Geoinf. 2018, 71, 43-55. [CrossRef]

82. Wurm, P.A. Suppression of germination and establishment of native annual rice by introduced para grass on an Australian monsoonal floodplain. Plant Prot. Q. 2007, 22, 106-112.

83. Williams, P.R.; Collins, E.M.; Grice, A.; Mike Nicholas, D.; Perry, J.J. The role of fire in germinating wild rice (Oryza meridionalis), an annual grass of northern Australian wetlands threatened by exotic grass invasion. Ecol. Manag. Restor. 2011, 12, 74-76. [CrossRef]

84. Wurm, P. A surplus of seeds: High rates of post-dispersal seed predation in a flooded grassland in monsoonal Australia. Austral. J. Ecol. 1998, 23, 385-392. [CrossRef]

85. Bayliss, P.; Ligtermoet, E. Seasonal habitats, decadal trends in abundance and cultural values of magpie geese (Anseranus semipalmata) on coastal floodplains in the Kakadu Region, northern Australia. Mar. Freshw. Res. 2017, 69, 1079-1091. [CrossRef]

86. Mollah, W.S. Humpty Doo: Rice in the Territory; The Australian National University, North Australia Research Unit (NARU): BBrinkin, NT, Australia, 1982; p. 48.

87. Fuller, D.Q.; Qin, L. Water management and labour in the origins and dispersal of Asian rice. World Archaeol. 2009, 41, 88-111. [CrossRef]

88. Purugganan, M.D.; Fuller, D.Q. The nature of selection during plant domestication. Nature 2009, 457, 843-848. [CrossRef] 
89. Winchell, E.; Dahl, R. Wild Rice: Production, Processing and Marketing; University of Minnesota, Agricultural Experiment Station: Minneapolis, MN, USA, 1984; Volume 29, p. 37.

90. Arunrat, N.; Pumijumnong, N.; Sereenonchai, S.; Chareonwong, U.; Wang, C. Assessment of climate change impact on rice yield and water footprint of large-scale and individual farming in Thailand. Sci. Total Environ. 2020, 726, 137864. [CrossRef] [PubMed]

91. Whitehead, P.J.; Saalfeld, K. Nesting phenology of magpie geese (Anseranas semipalmata) in monsoonal northern Australia: Responses to antecedent rainfall. J. Zool. 2000, 251, 495-508. [CrossRef]

92. Taylor, J.A.; Tulloch, D. Rainfall in the wet-dry tropics: Extreme events at Darwin and similarities between years during the period 1870-1983 inclusive. Aust. J. Ecol. 1985, 10, 281-295. [CrossRef]

93. Pillsbury, R.W.; McGuire, M.A. Factors affecting the distribution of wild rice (Zizania palustris) and the associated macrophyte community. Wetlands 2009, 29, 724-734. [CrossRef]

94. Shao, M.; Haas, M.; Kern, A.; Kimball, J. Identification of single nucleotide polymorphism markers for population genetic studies in Zizania palustris L. Conserv. Genet. Resour. 2019, 12, 451-455. [CrossRef]

95. Porter, R. Wildrice (Zizania L.) in North America: Genetic resources, conservation, and use. In North American Crop Wild Relatives; Greene, S., Williams, K., Khoury, C., Kantar, M., Marek, L., Eds.; Springer: Cham, Switzerland, 2019; Volume 2, pp. $83-97$.

96. Yu, X.; Chu, M.; Chu, C.; Du, Y.; Shi, J.; Liu, X.; Liu, Y.; Zhang, H.; Zhang, Z.; Yan, N. Wild rice (Zizania spp.): A review of its nutritional constituents, phytochemicals, antioxidant activities, and health-promoting effects. Food Chem. 2020, 331 , 127293. [CrossRef] [PubMed]

97. Atkins, T.; Lee, P.; Stewart, J. Growth of wild rice (Z. palustris L.) in fertilized flocculent sediments. J. Environ. Manag. 1992, 35, 217-228. [CrossRef]

98. Zhai, C.; Lu, C.; Zhang, X.; Sun, G.; Lorenz, K. Comparative study on nutritional value of Chinese and North American wild rice. J. Food Compos. Anal. 2001, 14, 371-382. [CrossRef]

99. Przybylski, R.; Klensporf-Pawlik, D.; Anwar, F.; Rudzinska, M. Lipid components of North American wild rice (Zizania palustris). J. Am. Oil Chem. Soc. 2009, 86, 553-559. [CrossRef]

100. Oelke, E.A.; Grava, J.; Noetzel, D.; Barron, D.; Percich, J.; Schertz, C.; Strait, J.; Stucker, R. Wild Rice Production in Minnesota; University of Minnesota: Minneapolis, MN, USA, 1982; p. 40.

101. Cho, S.; Kays, S.J. Aroma-active compounds of wild rice (Zizania palustris L.). Food Res. Int. 2013, 54, 1463-1470. [CrossRef]

102. Lu, B.-R.; Naredo, M.E.B.; Juliano, A.B.; Jackson, M.T. Hybridization of AA genome rice species from Asia and Australia II. Meiotic analysis of Oryza meridionalis and its hybrids. Genet. Resour. Crop Evol. 1997, 44, 25-31. [CrossRef]

103. Lu, B.-R.; Naredo, M.E.B.; Juliano, A.B.; Jackson, M.T. Taxonomic status of Oryza glumaepatula Steud. III. Assessment of genomic affinity among AA genome species from the New World, Asia, and Australia. Genet. Resour. Crop Evol. 1998, 45, 215-223. [CrossRef] 